\title{
Pregnancy and its outcome in women with and without surgical correction of Tetralogy of Fallot
}

\author{
Samsad Jahan ${ }^{1}$, Tripty Das², Shahnaz Rahman ${ }^{1}$, Md. Zahid Hossain ${ }^{4}$, Fateha Ferdous ${ }^{1}$, \\ Samira Humaira Habib 3 , Soma Saha ${ }^{3}$, Manzoor Mahmood ${ }^{4}$, Md. Harisul Hoque 4 \\ ${ }^{1}$ Department of Gynecology \& Obstetrics, BIRDEM, Dhaka, Bangladesh \\ 2Department of Gynecology \& Obstetrics, Bangabandhu Sheikh Mujib Medical University, Dhaka \\ ${ }^{3}$ Health Economics Unit, BADAS, Dhaka, Bangladesh. \\ 4 Department of Cardiology, Bangabandhu Sheikh Mujib Medical University, Dhaka \\ Address forCorrespondence \\ Dr Samsad Jahan Consultant and Associate Professor Department of Gynecology \& Obstetrics \\ BIRDEM, Dhaka, 122 Kazi Nazrul Islam Avenue, Dhaka -1000, Bangladesh, \\ E-mail: shelly_birdem@yahoo.com
}

\begin{abstract}
Two pregnent lady came with Tetralogy of Fellot (TOF) for antenatal care. One of them had been operated and the other one was not operated. One who had been operated delivered a healthy baby. The other one was medically managed with oxygen, propranolol and maintainance of hydration. She delivered a normal baby with normal delivery. In repaired Tetralogy of Fallot (rTOF), the risk of pregnancy is dependant on the degree of residual haemodynamic impairment. Where a good repair has been achieved, pregnancy is usually well tolerated in the absence of pregnancy complications such as pre-eclampsia. In patients with uncorrected Tetralogy of Fallot, attention to volume status should be continued during the early postpartum period. A reliable contraceptive plan should be made, permanent sterilization is a good alternative.
\end{abstract}

\section{Introduction}

Tetralogy of Fallot is a complex cyanotic heart disease consisting of ventricular septal defect (VSD), over-riding aorta, pulmonary stenosis and right ventricular hypertrophy. Although survival into adulthood is possible uncorrected Tetralogy of Fallot is rarely seen in pregnancy for several reasons. Most patients undergo surgical correction early in their life. After surgical correction, cardiac arrhythmias are seen in some patients although these typically are not a severe problem. ${ }^{1,5}$ Patients without residual defects after surgical correction tolerate pregnancy well. ${ }^{1-4}$ With uncorrected Tetralogy of Fallot pregnancy presents serious risks, including maternal mortality. 1,6 A good neonatal outcome can be expected in patients with corrected tetralogy of fallot and no residual defects. 1,2 Maternal mortality is $<1 \%$ but without correction the maternal mortality is $4 \%$ to $5 \%$ with a fetal loss rate of $30 \%$. Although the risk of congenital heart disease in the fetus is (15\% to $20 \%$ ) greater than the general population, the true incidence in patients with Tetralogy of Fallot is uncertain. ${ }^{1}$ Patients with previous corrective surgery should be evaluated for residual defects such as VSD. If present, consideration should be given to repair. 2,6 After surgical correction activity should be restricted to the point of preventing fatigue. Epidural anesthesia can be used provided the patient is adequately hydrated and it is carefully administered. So as not to further obstruct out flow and increase right to left shunting and to supplement oxygen as necessary. To present decrease in venus return with bearing down, operative vaginal delivery may be used to shorten the second stage of labour. This strategy is often applied in patients with corrected Tetralogy of Fallot, although it probably is not necessary. 1,2

\section{Case Report-TOF}

\section{Case Report-1}

A patient Mrs X, 26 years old was admitted into BIRDEM hospital with 38 weeks of pregnancy with lower abdominal pain for 5 days. She was a patient of Tetralogy of Fallot. Corrective surgery was done on 1993 at her 11 years of age. She had shortness of breath on exertion since childhood with occasional discoloration of nails aggravated on exertion. She also had several episodes of cyanotic spell in childhood.

Echocardiography and color Doppler showed Intact IAS, normal PV drainage, large sub aortic VSD, 50\% aortic override and pulmonary annulus adequate. Normal RVOF, PV thickened and systolic doming good size MPA, RPA, and LPAs. Right aortic arch. Angiogram consistent with TOF 
with good sized PA. Total correction of Tetralogy of Fallot was performed. After that she was doing well. During pregnancy echocardiography at term showed LVEF- $60 \%$ right sided volume overload, dilatation of RA and RV with good LV systolic function. As patient had gross cephalo-pelvic disportion, lower uterine cesarean section was done. A healthy male baby was weighted $2.9 \mathrm{~kg}$ and was delivered without TOF or other congenital abnormality of the foetus. Breast-feeding was given Post operative period was uneventful and discharged from hospital on her $4^{\text {th }}$ postoperative day.

\section{Case Report 2}

Mrs X, 28 years old was admitted into BSMMU on 30/08/08 with the complaints of 36th weeks pregnancy with respiratory distress and chest pain for the last 3 months. She was a known case of Tetralogy of Fallot. On admission her BP was $140 / 100 \mathrm{mmHg}$, pulse $80 \mathrm{~b} /$ minute. She was referred to a cardiologist. On examination Cyanosis ${ }^{+}$, clubbing present pulse $110 / \mathrm{mm}$, BP 140/100mmHg, heart $\mathrm{S}_{1} \mathrm{~S}_{2}$ audible systolic murmur in the pulmonary area, lungs clear, $\mathrm{O}_{2}$ inhalation, tablet propranolol, maintenance of adequate hydration. The patients delivered a healthy male baby of about $2 \mathrm{~kg}$ per vaginally. Slight perineal tear occurred and repaired in layers. She was given Inj Ceftriaxone, Inj Metronidazale and Inj Gentamicin. She was doing well postnatally and discharged from hospital on $3^{\text {rd }}$ postnatal day after reviewing and advices of cardiologist.

\section{Discussion}

TOF is the must common form of congenital cyanotic heart disease. With advances in cardiac surgery and medication increasing numbers of women with TOF are reaching their childbearing years and embarking on pregnancy. Uncorrected Tetralogy of Fallot is a cyanotic condition characterized by decreased arterial oxygen saturation and polycythemia. Pregnancy can cause further decomposition because the decreased systemic vascular resistance increases the right to left shunt; shunting is also inceased by a rise in the pulmonary vascular resistance resulting from the stress of labor. With uncorrected Tetralogy of Fallot, $40 \%$ of women develop heart failure during pregnancy and $12 \%$ die; the fetal mortality rate in $36 \%$. Pregnancy management includes bed rest, oxygen therapy and inotropic support as necessary. Because the decrease in systemic vascular resistance can be life threatening, epidural or spinal anesthesia should be avoided. Intravenous medication and paracervical or pudendal block can be utilized and the second stage of labour should be shortened. ${ }^{7}$

\section{Conclusion}

In repaired Tetralogy of Fallot (r TOF), the risk of pregnancy is dependant on the degree of residual haemodynamic impairment. Where a good repair has been achieved, pregnancy is usually well tolerated in the absence of pregnancy complications such as pre-eclampsia. In patients with uncorrected Tetralogy of Fallot, attention to volume status should be continued during the early postpartum period. A reliable contraceptive plan should be made; permanent sterilization is a good alternative. ${ }^{6}$

\section{References}

1. Singh H. Bolton PJ, Oakley CM. (1982). Pregnency after Surgical correction of Tetralogy of Fallot. British Medical Journal 285; 168-170.

2. Nissenkorn A, Friedman S, Schonfeld A. Ovadia J (1984). Fetomaternal outcome in pregnancies after total correction of the Tetralogy of Fallot. International Surgery 69; 125-128.

3. Velotman GR, Connolly HM, Grogan M, Ammash NM, Warner CA. Outcome of pregnancy in women with tetralogy of fallot. J Am Coll Cardiol 2004. 44; 174-180

4. Patton DE, Lee W, Cotton DB et al (1990). Cyanotic maternal heart disease in pregnancy. Obstetrical and Gynaecological Survey 45. 594-600.

5. Whittenmore R, Hobbins JC, Engle MA. Pregnancy and its outcome in women with and without surgical treatment of congenital heart disease. Am J Cardiol (1982) 50; 64.

6. David K, James. High Risk Pregnancy, Management options. Second Edition 694-695.

7. Katharine D Wenstrom, Maureen P Malee. Medical and surgical complications of pregnancy Danforth's obstetrics and Gynaecology. $8^{\text {th }}$ edition; Chapter 23: 327-361. 